\title{
WILEY-VCH
}

1 DOI: 10.1002/ ((please add manuscript number))

2 Article type: Full Paper

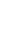
1

\section{Synthesis of Methacrylate-Terminated Block Copolymers with Reduced Transesterification by Controlled Ring-Opening Polymerization}

Laura A. Ruiz-Cantu ${ }^{a}$, Amanda K. Pearce ${ }^{b}$, Laurence Burroughs ${ }^{b}$, Thomas M. Bennett ${ }^{c}$, Catherine E. Vasey ${ }^{b}$, Ricky Wildman ${ }^{a}$, Derek J. Irvine ${ }^{a *}$, Cameron Alexander $^{b *}$ and Vincenzo $\operatorname{Taresco}^{b *}$

Dr. L. A. Ruiz-Cantu, Dr., Prof. R. Wildman, Prof. D.J. Irvine,

Faculty of Engineering, University of Nottingham, University Park, Nottingham, NG7 2RD, UK.

Dr. T. M. Bennett

School of Chemistry, University of Nottingham, University Park, Nottingham NG7 2RD, UK. Dr. A. K. Pearce, Dr. L. Burroughs, C. E. Vasey, Prof. C. Alexander and Dr. V. Taresco. School of Pharmacy, University of Nottingham, University Park, Nottingham NG7 2RD, UK.

E-mail: $\quad$ derek.irvine@nottingham.ac.uk, cameron.alexander@nottingham.ac.uk vincenzo.taresco@nottingham.ac.uk.

\section{Abstract}

This work presents a robust method to achieve the synthesis of low molecular weight polyesters via ring-opening polymerization (ROP) initiated by 2-hydroxyethyl-methacrylate (HEMA) when using triazabicyclodecene (TBD) as catalyst. The effect that the HEMA:TBD ratio has upon the final reaction rate and final polymer molecular architecture is discussed. The optimum HEMA:TBD ratio and reaction conditions required to minimize competing transesterification reactions were determined, in order to synthesize successfully the target ROP macromonomer species containing only a single 2-methacryloyloxyethyl end-group. Additionally, to confirm the terminal end-group fidelity of the product macromonomers and confirm TBD utility for block copolymer manufacture, a small series of di-block polyesters were synthesized using TBD and shown to exhibit good control over the final polymer structure whilst negating the side transesterification reactions, irrespective of the monomers used.

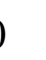




\section{WILEY-VCH}

\section{Introduction}

Synthetic aliphatic polyesters, such as poly(lactic acid) (PLA), polycaprolactone (PCL), or polycarbonates such as poly(trimethylene carbonate) (PTMC) and their copolymers are widely used for pharmaceutical and environmental applications due to their controllable biodegradability and low cost of production. ${ }^{[1,2]}$ To extend their use into more demanding applications, aliphatic polyesters with a wider variety of terminal or side-chain functionality are required ${ }^{[3,4]}$ For example, the introduction of a reactive double-bond, as either a side chain or an end-terminus on the main polymeric backbone, has paved the way for the production of highly functional copolymers where the functionality can be used as platform for postfunctionalization or further polymerization. ${ }^{[5]}$ In particular, the free hydroxyl group of 2hydroxyethylmethacrylate (HEMA) has been exploited as a ring-opening polymerization (ROP) initiator for the production of polyesters bearing a methacrylate terminus. ${ }^{[6]}$ These HEMA-terminated-polyester macromonomers have been used in copolymerization with other (metha)acrylic monomers, ${ }^{[7]}$ to produce graft-copolymers via controlled radical polymerization techniques such as ATRP and RAFT. ${ }^{[8,9]}$ However, the majority of the HEMA-based polyesters and polycarbonates, including the examples reported above, have been prepared using Sn based catalysts. ${ }^{[10-14]}$ Unfortunately, Sn-residues can be difficult to remove during polymer purification, which may compromise the quality of the final product and the potential applicability. ${ }^{[15]}$ An alternative route to polyesters utilizes enzymes as the catalyst system. ${ }^{[16]}$ However, enzyme catalyzed ROP (eROP) generally results in slow reactions with limited control over the final polymer architecture. ${ }^{[17]}$ In HEMA-initiated Lipase catalyzed eROP, even at low monomer conversion, numerous unwanted by-products are routinely obtained. This has been attributed to the low reaction selectivity of the enzyme, which allows competition between ROP and other transesterification processes. ${ }^{[16,17]}$ The use of triazabicyclodecene (TBD) as a catalyst for ROP has been demonstrated with a variety of cyclic monomers, resulting in the 


\section{WILEY-VCH}

synthesis of polymers with controlled molecular weight and polydispersity. ${ }^{[18]}$ The enhanced catalytic activity of TBD when compared with other organo-catalysts such as 1,8Diazabicyclo[5.4.0]undec-7-ene (DBU) and 4-Dimethylaminopyridine (DMAP) results from its ability to activate both monomer and initiator simultaneously. ${ }^{[19]}$

Building on these previous reports, the present study focuses on the development of a synthetic strategy which ensures good selectivity towards polymerization when using an $\alpha, \omega$-functional initiator such as HEMA, without compromising the end-group functionality. The reported method shows that TBD can be used as a catalyst to obtain HEMA-terminated-polyesters from three classes of monomer while demonstrating good control over the final polymer structure. These monomers, D,L-lactide (LA), $\varepsilon$-caprolactone (CL) and trimethylene carbonate (TMC), were chosen to exemplify a wide range of polymers commonly produced by ROP. Previous reports of TBD catalyzed ROP have suggested that implementing the correct initial initiator:catalyst ratio (HEMA:TBD in this case) is of vital importance for maintaining polymerization control, due to the dual nature of the catalyst activating both monomer and initiator. $^{[18]}$ Applying incorrect ratios and/or conditions can generate unwanted prepolymerization and concomitant acyl transfer side reactions. Therefore, we conducted a systematic study of the extent of HEMA transesterification by varying the initial HEMA:TBD ratio, to determine the optimum initiator:catalyst feed that would minimize undesired side transesterification reactions in the synthesis of a target set of low molecular weight polymers. To achieve the desired low molecular weight materials (i.e. DP's in the region $8-45$ ), these experiments require relatively high HEMA concentrations and so are susceptible to the onset of side reactions. The present work has identified the reaction conditions which allowed the successful production of mono(methyl)acrylated polymers with well-defined structures and molecular weights, irrespective of the monomers used. More specifically, high conversion of monomer into polymers as well as controlled molecular weight with respect to the initial $[\mathrm{M}]:[\mathrm{I}]$ feed-ratio, and polydispersitiy below 1.3 were simultaneously achieved. By identifying the 


\section{WILEY-VCH}

correct ratios of monomer, initiator and catalyst, the reported synthetic methodology has overcome the previously described unsuccessful attempts to use TBD as catalyst in HEMAinitiated ROP due to the formation of uncontrollable by-products. ${ }^{[20]}$ Finally, to validate the overall robustness and versatility of the proposed synthetic strategy, the chain-extension of a HEMAPCL polyester from the hydroxyl-end group, to generate mixed block copolymers, was successfully demonstrated.

\section{Experimental Section}

\subsection{Materials and Methods}

D,L-lactide 99\% (LA) was purchased from Alfa Aesar (by Thermo Fisher Scientific). Trimethylene carbonate (TMC) was purchased from Polyscience. $\varepsilon$-caprolactone (CL), extra dry dichloromethane (DCM), deuterated chloroform $\left(\mathrm{CDCl}_{3}\right)$ and triazabicyclodecene (TBD) were acquired from Sigma Aldrich. Hexane, diethyl ether and methanol were obtained from Fisher. In all cases the vials were dried in an oven at $100{ }^{\circ} \mathrm{C}$ overnight prior to use, and the HEMA and DCM were stored over molecular sieves and under an inert atmosphere.

\subsection{Synthesis}

HEMA Transesterification Kinetics in Presence of TBD. In a typical procedure, precalculated amounts of HEMA and TBD were mixed in $3 \mathrm{~mL}$ of $\mathrm{DCM}$ at room temperature to commence the chemical transformations. As the reactions proceeded, aliquots of the solution were taken at predetermined time points $(0,5,15$ and $60 \mathrm{~min})$ and were analyzed by ${ }^{1} \mathrm{H}$ NMR spectroscopy. The quantities of HEMA and TBD were selected in order to mimic the reaction conditions in which $1000 \mathrm{mg}$ of $\varepsilon \mathrm{CL}(8.77 \mathrm{mmol})$ would be present as the initial monomer loading. Namely, HEMA was used at two distinct feed levels which mimicked a hypothetical final targeted molecular weight of $2000 \mathrm{Da}$ and 10,000 Da respectively. They were defined as the "high" and "low" levels of HEMA (High: $0.46 \mathrm{mmol}, 60 \mathrm{mg}$ and Low: $0.10 \mathrm{mmol}, 13 \mathrm{mg}$ ). 


\section{WILEY-VCH}

120 TBD was also systematically introduced and two levels to reproduce the limiting reaction

121 conditions of 1 and $2.5 \%$ mol:mol ratios when compared to the monomer, i.e. these are the

122 "low" (12 mg) and "high" (30 mg) TBD definitions. Four different boundary transesterification

123 scenarios were then applied and analyzed with respect to the result of the ROP reaction. An

124 unpaired t-test ( $<<0.05$ indicating significant difference) analysis was performed at each time-

125 point for each selected ratio.

126 HEMA Initiated ROP of the Cyclic Monomers. ROP experiments were performed adopting

127 'standard laboratory' conditions, i.e. ambient temperature and atmosphere. ${ }^{[21]}$ The desired

128 amount of cyclic monomer (500-1000 mg) and HEMA-initiator ([M]:[I] or DP 0 ratios targeted

129 to produce final molar masses of either 2500 or $5000 \mathrm{Da}$ ) were weighed into a vial, which had

130 been dried in an oven at $100{ }^{\circ} \mathrm{C}$ overnight and capped with a rubber septum. DCM (10 ml), was

131 then added via syringe and the mixture was allowed to dissolve at room temperature (RT) for

132 5-10 minutes. Varying amounts of catalyst (from 1-2.5\% $\mathrm{mol} / \mathrm{mol}$ of TBD with respect to

133 monomer) were then added to trigger the ring-opening process. Reactions were observed to

134 occur in time-frames ranging from 1-240 minutes, according to the

135 monomer:initiator :solvent :catalyst adopted ratios. The reaction was terminated by catalyst

136 deactivation upon adding an acidic solution and the polymer purified by means of multiple

137 precipitation steps and dried in a vacuum oven.

138 HEMAPCL (Entries 7 and 8, Table 1) Initiated ROP. The required amount of cyclic

139 monomer (500-1000 mg) and PCLHEMA-initiator to give the $[\mathrm{M}]:[\mathrm{I}]$ ratios needed to achieve

140 a targeted extension of 10 units for TMC and 35 units for LA, were weighed into a vial which

141 had been dried in an oven at $100{ }^{\circ} \mathrm{C}$ overnight and capped using a rubber septum. DCM (10

$142 \mathrm{ml}$ ), which had been dried over molecular sieves and kept under inert gas environment, was

143 then added via syringe and the mixture was allowed to dissolve at RT for 5-10 minutes. A

144 certain amount of TBD equal to $1 \%$ mol:mol compared to the amount of monomer was then 


\section{WILEY-VCH}

145 added to trigger the ring-opening process. The TBD was quenched by adding an acid solution

146 after 3 minutes to terminate the reaction.

147

148

150

151

152

153

154

155

156

157

158

159

160

161

162

163

164

165

166

167

168

169

\subsection{Polymer Characterization}

HEMA-PDLLA. Characterization data was obtained after three precipitation cycles in hexane and diethyl ether. ${ }^{1} H \operatorname{NMR}\left(400 M H z, C D C l_{3}\right): \delta 6.14(\mathrm{~s}, 1 \mathrm{H}), 5.61(\mathrm{~s}, 1 \mathrm{H}), 5.19(\mathrm{~m}$, $\left.2 \mathrm{H}^{*}[\mathrm{M}]:[\mathrm{I}]\right), 4.36(\mathrm{~m}, 5 \mathrm{H}), 1.95(\mathrm{~m}, 3 \mathrm{H}), 1.59\left(\mathrm{~m}, 6 \mathrm{H}^{*}[\mathrm{M}]:[\mathrm{I}]\right)$, presence of residual catalyst and solvents (from synthesis and purification) can be spotted. Conversion: monomer to final polymer conversion determined by NMR was 90-95\% with a recorded gravimetric yield of 70$75 \%$ (700-750 mg when aiming at theoretical $1000 \mathrm{mg}$ of polymer). Further characterization shown in Table 1. Molecular Weight: As all polymers exhibited transesterification levels below $10 \%, \mathrm{M}_{\mathrm{n}}$ values were evaluated by ${ }^{1} \mathrm{H}$ NMR. ${ }^{[6,8]}$

HEMA-PTMC. Characterization data was obtained after three precipitation cycles in hexane and diethyl ether. ${ }^{l} H N M R\left(400 M H z, C D C l_{3}\right): \delta 6.14(\mathrm{~s}, 1 \mathrm{H}), 5.61(\mathrm{~s}, 1 \mathrm{H}), 4.39(\mathrm{~m}, 4 \mathrm{H}), 4.25$ $\left(\mathrm{m}, 4 \mathrm{H}^{*}[\mathrm{M}]:[\mathrm{I}]\right), 3.74(\mathrm{~m}, 2 \mathrm{H}), 2.04(\mathrm{~m}, 2 \mathrm{H} *[\mathrm{M}]:[\mathrm{I}]), 1.96(\mathrm{~m}, 3 \mathrm{H})$, presence of residual catalyst and solvents (from synthesis and purification) can be spotted. Conversion: monomer to final polymer conversion determined by NMR was $90-95 \%$ with a recorded gravimetric yield of 50-60\% (500-600 $\mathrm{mg}$ when aiming at theoretical $1000 \mathrm{mg}$ of polymer). Further characterization shown in Table 1. Molecular Weight: As all polymers exhibited transesterification levels below $10 \% \mathrm{M}_{\mathrm{n}}$ values were evaluated by ${ }^{1} \mathrm{H} \mathrm{NMR} .{ }^{[6]}$

HEMA-PCL. Characterization data was obtained after purification via three cycles of precipitation in cold $\mathrm{MeOH} .{ }^{1} H$ NMR: $\left(400 \mathrm{MHz}, \mathrm{CDCl}_{3}\right): \delta 6.14(\mathrm{~s}, 1 \mathrm{H}), 5.61(\mathrm{~s}, 1 \mathrm{H}), 4.40-$ $4.30(\mathrm{~m}, 4 \mathrm{H}), 4.08\left(\mathrm{t}, 2 \mathrm{H}^{*}[\mathrm{M}]:[\mathrm{I}]\right), 3.68(\mathrm{~m}, 2 \mathrm{H}), 2.33\left(\mathrm{t}, 2 \mathrm{H}^{*}[\mathrm{M}]:[\mathrm{I}]\right), 1.97(\mathrm{~m}, 3 \mathrm{H}), 1.67(\mathrm{~m}$, $\left.4 \mathrm{H}^{*}[\mathrm{M}]:[\mathrm{I}]\right), 1.41\left(\mathrm{~m}, 2 \mathrm{H}^{*}[\mathrm{M}]:[\mathrm{I}]\right)$, presence of residual catalyst and solvents (from synthesis and purification) can be spotted. Conversion: monomer to final polymer conversion determined by NMR was $75 \%$ with a recorded gravimetric yield of $70 \%$ (700 mg when aiming at theoretical 


\section{WILEY-VCH}

$1701000 \mathrm{mg}$ of polymer). Further characterization is shown in Table 1. Molecular Weight: When

171 the degree of transesterification was below $10 \%, \mathrm{M}_{\mathrm{n}}$ values were evaluated by ${ }^{1} \mathrm{H} \mathrm{NMR} .{ }^{[6]}$

172 HEMAPCL-PTMC. Characterization data was obtained after purification via three cycles of

173 precipitation in cold hexane-diethyl ether: ${ }^{l} H N M R\left(400 \mathrm{MHz}, \mathrm{CDCl}_{3}\right): \delta 6.14(\mathrm{~s}, 1 \mathrm{H}), 5.61(\mathrm{~s}$,

$1741 \mathrm{H}), 4.40-4.20\left(\mathrm{~m}\right.$, from HEMA and TMC), $4.08\left(\mathrm{t}, 2 \mathrm{H}^{*} 35\right), 3.80(\mathrm{~m}, 2 \mathrm{H}), 2.33\left(\mathrm{t}, 2 \mathrm{H}^{*} 35\right)$,

$1751.97(\mathrm{~m}, 3 \mathrm{H}), 2.04(\mathrm{~m}, 2 \mathrm{H} *[\mathrm{M}]:[\mathrm{I}]), 1.67\left(\mathrm{~m}, 4 \mathrm{H}^{*} 35\right), 1.41\left(\mathrm{~m}, 2 \mathrm{H}^{*} 35\right)$, presence of residual

176 catalyst and solvents (from synthesis and purification) can be spotted. Conversion: TMC

177 monomer to final block copolymer monomer conversion determined by NMR was $80 \%$ with a

178 recorded gravimetric yield of $70 \%$. Further characterization shown in Table 1. Molecular

179 Weight: As all polymers exhibited transesterification levels below $10 \% \mathrm{M}_{\mathrm{n}}$ values were

180 evaluated by ${ }^{1} \mathrm{H}$ NMR. ${ }^{[6]}$

181 HEMAPCL-PDLLA. Characterization data was obtained after purification via three cycles of 182 precipitation in cold hexane-diethyl ether: ${ }^{1} \mathrm{H} N M R\left(400 \mathrm{MHz}, \mathrm{CDCl}_{3}\right):{ }^{1} \mathrm{H} \mathrm{NMR}(400 \mathrm{MHz}$, $\left.183 \mathrm{CDCl}_{3}\right): \delta 6.14(\mathrm{~s}, 1 \mathrm{H}), 5.61(\mathrm{~s}, 1 \mathrm{H}), 5.19\left(\mathrm{~m}, 2 \mathrm{H}^{*} 28\right), 4.40-4.20(\mathrm{~m}, 5 \mathrm{H}$ from LA end group 184 and HEMA), $4.08\left(\mathrm{t}, 2 \mathrm{H}^{*} 35\right), 3.68(\mathrm{~m}, 2 \mathrm{H}), 2.33\left(\mathrm{t}, 2 \mathrm{H}^{*} 35\right), 1.97(\mathrm{~m}, 3 \mathrm{H}), 1.67(\mathrm{~m}$, $\left.1854 \mathrm{H}^{*} 35\right), 1.59\left(\mathrm{~m}, 6 \mathrm{H}^{*} 28\right) 1.41\left(\mathrm{~m}, 2 \mathrm{H}^{*} 35\right)$, presence of residual catalyst and solvents (from 186 synthesis and purification) can be spotted. Conversion: LA monomer to final block copolymer 187 monomer conversion determined was $80 \%$ with a recorded gravimetric yield of $75 \%$. Further 188 characterization shown in Table 1. Molecular Weight: As all polymers exhibited 189 transesterification levels below $10 \% \mathrm{M}_{\mathrm{n}}$ values were evaluated by ${ }^{1} \mathrm{H} \mathrm{NMR} .{ }^{[6]}$

$190 \quad 2.4$ Characterization Methodologies

191 NMR Spectroscopy: ${ }^{1} \mathrm{H}$ NMR spectra were recorded on a Bruker AV3400 $400.1 \mathrm{MHz}$ spectrometer using $\mathrm{CDCl}_{3}$ as the solvent reference $(7.26 \mathrm{ppm})$. Chemical shifts are expressed

193 in parts per million (d) downfield from internal standard tetramethylsilane.

194 2D-NMR Spectroscopy: ${ }^{1} \mathrm{H}-{ }^{13} \mathrm{C}$ heteronuclear single quantum correlation (HSQC) and ${ }^{1} \mathrm{H}-$

$195{ }^{13} \mathrm{C}$ heteronuclear multiple-bond correlation (HMBC) (one-bond suppression) spectra were 


\section{WILEY-VCH}

196 recorded on a Bruker AV $3500\left(500.1 \mathrm{MHz}\right.$ for ${ }^{1} \mathrm{H}, 125.8 \mathrm{MHz}$ for $\left.{ }^{13} \mathrm{C}\right)$ spectrometer using

$197 \mathrm{CDCl}_{3}$ as the solvent reference $\left(7.26 \mathrm{ppm}\right.$ for ${ }^{1} \mathrm{H}, 77.16 \mathrm{ppm}$ for $\left.{ }^{13} \mathrm{C}\right)$. The final $\mathrm{HSQC}$ spectrum

198 depicts a peak for each unique pair of directly coupled nuclei $\left({ }^{1} \mathrm{H}-{ }^{13} \mathrm{C}\right)$. The final $\mathrm{HMBC}$

199 spectrum depicts correlations between coupled nuclei pairs $\left({ }^{1} \mathrm{H}-{ }^{13} \mathrm{C}\right)$ that are separated by two

200 - four bonds, with direct one-bond correlations suppressed.

201 GPC Analysis: Gel Permeation Chromatography (GPC) was performed by using a PL50+ 202 Polymer Laboratories system. An RI constructed calibration curve from PMMA (Mn range 350000-620 Da) was adopted to analyze polymer molar masses. 2 PL mixed-D columns at $50{ }^{\circ} \mathrm{C}$ were employed, using $0.1 \% \mathrm{LiBr}$ DMF as the mobile phase with a flow rate of $1 \mathrm{ml} / \mathrm{min}$.

\section{Results and Discussion}

A number of prior reports have shown that TBD is an efficient acyl-transfer and transesterification catalyst. Its high activity is linked to its ability to interact with both initiator and monomer (Scheme 1), ${ }^{[22]}$ and it has been proposed to follow a pseudo bifunctional nucleophilic catalytic mechanism. ${ }^{[23]}$ This feature allows TBD to catalyze the ROP reaction of

$217 \varepsilon$-CL, commonly known as refractive monomer in ROP process, without the need to adopt a 218 co-catalyst (for example a thiourea) that is required for alternative organocatalyst such as 219 DBU. ${ }^{[22]}$ It the same way tin octoate, which is currently the most widely used catalyst for ROP, exploits a coordination-insertion process allowing interactions with both initiator (nucleophile)

221 and monomer without the need of a co-catalyst. ${ }^{[20]}$ However, the main drawbacks related with 222 tin octoate are the intrinsic toxicity and the high temperature required to activate any ROP 


\section{WILEY-VCH}

reactions enabling intermolecular and intramolecular esterification to occur and thus broadening the final polymer molecular polydispersity. ${ }^{[22]}$.

On the basis of this, in the present work, it was speculated that TBD can also trigger a self-acyl transfer of the methacrylic group of HEMA, producing ethylene bis-methacrylate and ethylene glycol (Scheme 2).

This was supported by both species being detected in the ${ }^{1} \mathrm{H}$ NMR of the reaction mixture (Figure S1). This HEMA self-transesterification can compete, as side reaction, with the ROP process by altering the concentration and/or identity of the active initiator. Consequently, by affecting the $[\mathrm{M}]:[\mathrm{I}]$ ratio, the presence of this competitive acyl transfer process can severely affect the quality of the final polymer in terms of molecular weight and architecture.

In order to evaluate the magnitude of the effect of the acyl transfer reaction, a kinetic study was conducted by systematically varying the "high" and "low" [HEMA]:[TBD] ratios to mimic the concentration ranges applied in an ideal ROP reaction to synthesize a $2000 \mathrm{Da}$ and 10,000 Da product. The results of these experiments are compared in Figure 1 and the supporting NMR data are shown in Figure S1.

These data show that transesterification is more pronounced when both the concentrations of HEMA and TBD are at the "high" values, reaching almost $25 \%$ of transesterification within 5 minutes. However, when the amount of HEMA was kept "high", while the amount of TBD was reduced to "low", a reduction in transesterification was observed during the same time-frame, namely, only $8-10 \%$ of unwanted reaction was detected. Furthermore, when HEMA was reduced ("low"), as expected, the kinetics of the reaction considerably reduced and, independently of the TBD concentration, only 5-6\% of transesterification occurred after 5 min. An unpaired t-test ( $<<0.05$ indicating significant difference) analysis was performed at each time-point and confirmed that significant differences were observed at each time point between the two selected initiator:catalyst ratios. Therefore, this set of experiments demonstrated that keeping the HEMA concentration at the "low" level is important to reduce side-reactions. 


\section{WILEY-VCH}

249 We subsequently explored the ability of TBD to selectively catalyze ROP of lactide (LA), $\varepsilon^{-}$

250 caprolactone (CL) and trimethylene carbonate (TMC) monomers, ${ }^{[18,22,23]}$ while controlling

251 methacrylate transfer side reactions. LA polymerizations (Figure 2) were performed with

252 [LA]:[HEMA] ratios targeting final molecular weights of $5000 \mathrm{Da}$ and $6500 \mathrm{Da}$ (i.e. $\mathrm{DP}_{0}$ of 35

253 and 45) respectively.

254 PDLLA polymers were produced within seconds of introducing the catalyst at room 255 temperature. The reactions exhibited good control of the molecular weight ( $Đ$ ranging from

1.18-1.21, Table 1), which was in agreement with prior literature reports. ${ }^{[18,23]}$

The experimental DP of the PDLLA products (Entries 1 and 2, Table 1) were observed to match

the theoretical DP and subsequent analysis by ${ }^{1} \mathrm{H}-\mathrm{NMR}$ (Figure 2) confirming the presence of only a single set of methacrylic proton peaks indicating a good control of the polymer and no evidence of transesterification.

Furthermore, 2D-NMR experiments indicated that the ROP mechanism was predominant, with

the HSQC spectrum (Figure 3) showing a single acrylic (vinylic) carbon peak directly correlated to the two methacrylic protons (see inset Figure 3A). This confirms the presence of only a single HEMA-terminated group per polymeric chain. The HMBC spectrum further confirms a single correlation between the two methacrylic protons and both a single carbonyl and methyl group species (Figure 3B), with no additional peaks related to the methacrylic protons observed.

Good control over the final polymer features was also observed for the PTMC monomethacrylic polymer (Figure 4). Despite a change in the molecular structure of the cyclic monomer, fast kinetics similar to that exhibited by the PDLLA were observed. The final molecular weight was in agreement with the target of approximately $5000 \mathrm{Da}$ as confirmed by 


\section{WILEY-VCH}

275 To exemplify further the importance of the TBD-catalyzed ring-opening kinetics to the 276 production of defined polymer structures, the polymerization of $\varepsilon$-CL was then explored, due

277 to its lower ROP reactivity when compared to monomers such as LA. ${ }^{[18]}$ In agreement with the

278 literature, a slower rate of polymerization was observed for CL when compared to LA and TMC 279 and as a consequence the overall reaction was noted to be less controlled (Entry 4-6, Table 1 280 and Figure S3). Analysis of the final products showed that this was due to both the tendency 281 of the PCL terminal chain group to transesterify ${ }^{[18,24]}$ and an increased level of HEMA:TBD 282 interaction prior to polymerization which generated a diol initiator over time. When the $1 \%$ 283 mol:mol of TBD:Monomer ratio was used as for TMC and LA, no CL polymerization was 284 observed. This was attributed to the slow ROP kinetics and consequent dominance of the self285 transesterification kinetics of HEMA. Thus, a TBD:monomer ratio of $2.5 \%$ mol:mol was then 286 adopted. Polymerization was observed, and the reaction was complete within 120-240 min (see 287 Entry 4, Table 1 and Figure S2). The formation of sub-products was evident in the NMR analysis (Figures S3 and Figure 5 see methacrylate peaks inset). Thus, it was not possible to evaluate the final molecular weight by ${ }^{1} \mathrm{H}$ NMR, due to a splitting of the HEMA peaks and the contribution to the polymeric CL peaks arising from polymer formed from other initiating species such as the diol. As a consequence, a broader value of $Đ$ (1.55) was observed in the GPC data. The ${ }^{1} \mathrm{H}-\mathrm{NMR}$ spectra showed that the transesterification occurred over time as the splitting of the vinyl peaks in the 6.20 to $5.50 \mathrm{ppm}$ region increased as the reaction proceeded (see Figure S2-S3). This splitting was in accordance with the initial screening reported in Figure S1.

296 A series of 2D-NMR experiments were performed, to clarify the presence of both HEMA and methacrylic end-capped terminal groups and to link unambiguously the vinyl peak splitting to a transesterification process. The HSQC spectrum (Figure S3) showed the presence of two different types of carbons correlating to the two sub-families of methacrylic proton peaks. This

300 indicates the presence of two unique end-capping methacrylic groups, and thus an undesired 


\section{WILEY-VCH}

301 end-terminal methacrylic group in addition to the HEMA-initiation end-terminus. This was

further exemplified in the HMBC spectra, where two sets of multiple-bond correlations between the two types of methacrylic protons and both of the two kinds of carbonyl and methyl group species were observed (Figure S4).

By reducing the TBD loading to $1.5 \%$ mol:mol, HEMAPCL could be synthesized with a significant reduction of the side acyl transfer reactions (see ${ }^{1} \mathrm{H}-\mathrm{NMR}$, Figure 5, Figure S5 and Entry 6, Table 1 ).

Using these conditions and restricting the reaction time to $120 \mathrm{~min}$, an average conversion of monomer to polymer of circa $60-70 \%$ could be reached before the reaction was quenched. This confirmed that by reducing the amount of TBD, and thus tuning the initial HEMA:TBD ratio, there was a drop in the undesired transesterification reaction at the $1.5 \%$ mol:mol when compared with the PCL synthesized using $2.5 \%$ mol:mol of catalyst (see inset within Figure 5). At this TBD concentration only 2 to $5 \%$ of bis-methacrylic chains were observed in a series of experiments with targeted molecular weights of approximately 2500 and $5000 \mathrm{Da}$ (Entries 5 and 6, Table 1) compared to the $\sim 50 \%$ observed in prior literature by using Lipase catalysts. ${ }^{[16]}$ Finally, in order to assess the level of retention of the hydroxyl group at the end of each polymeric chain and thus confirming good end group fidelity, HEMA initiated PCL with a targeted $\mathrm{DP}_{0}$ of 35 (see Entry 6, Table 1) was then employed as a macroinitiator for the synthesis of block copolymers with TMC or LA as the chain extending monomers. The targeted $\mathrm{DP}_{0}$ for the second TMC block was 10 units whilst for LA was 35 units (i.e. $35+\mathrm{DP}_{\mathrm{o}} 10$ of TMC or $35+\mathrm{DP}_{\mathrm{o}} 35$ of LA). After the polymerization of TMC and post-purification steps an experimental DPe of 8 was observed (Entry 7, Table 1 and Figure 6). For the LA extension, a conversion of $80 \%$ in the second block of PDLLA was achieved to reach a DP of 28 (Entry 8 Table 1), which is what would be expected from the conversion corrected target. In both cases, the characteristic NMR peaks attributed to the main chains TMC and LA were present in spectra of the final copolymer as were the characteristic end groups for the second added monomer 


\section{WILEY-VCH}

327 (Figure 6 Left). Increases in the molecular weight of the polymers compared to that of the 328 HEMA initiated PCL-macroinitiator (Figure 6 Right) were evident in the GPC chromatograms, 329 i.e. $4307 \mathrm{Da}(Đ$ of 1.13$)$ to $6295 \mathrm{Da}(Đ$ of 1.09$)$ and $8125 \mathrm{Da}(Đ$ of 1.15$)$ for TMC and LA 330 respectively. This confirmed the formation of block copolymers. The existence of only a single 331 peak for the sequential block copolymers proved the successful control over the addition of the 332 second monomer onto the initial HEMAPCL macroinitiator.

333 The success of the regrowth from the macro-initiator in this proof-of-concept experiment 334 confirmed both the control of the reaction conditions for the production of block copolymers, as well as the end group (hydroxyl group in this case) fidelity that can be achieved in the production of the macro-initiator. The increase in molecular weight shown in the GPC traces

337 (Entries 7 and 8, Table 1) to produce single monodispersed peaks confirmed both the availability of the hydroxyl PCL terminal group to initiate the polymerization of the second sequential block and the level of control exercized over the extension step on the initial HEMAPCL macro-initiator.

\section{Conclusions}

The synthetic strategy reported here is the first example of successful HEMA-initiated ROP catalyzed by TBD. To highlight the novelty and the broad applicability of the synthetic methodology developed in the present work, it is important to note that in recent work it has

349 been reported that when TBD was adopted, as catalyst of ROP reactions, with HEMA as nucleophilic initiator, no controlled polymerization events were observed due to a series of

351 uncontrollable side reactions. ${ }^{[20]}$ Consequently, tin octoate was needed to prepare the targeted 352 (metha)acrylated-macromolecules. On the contrary, the present study has demonstrated that TBD indeed can be employed as an active and selective catalyst for HEMA-initiated ROP of 


\section{WILEY-VCH}

354 LA, TMC, and CL, to synthesize polymers and block copolymers with controlled molecular weight, low polydispersity and a mono-methacrylate final architecture (see Table 1).

Success in achieving the target ROP while minimizing polyester transesterification reactions

was demonstrated to be minimal when fast polymerization kinetics were obtained from the monomer of choice. In the cases where monomer types presenting slower kinetics were employed, both significant levels of "by-products" $(>50 \%)$ and subsequent loss of control over

360 the molecular structure of the polymer was observed. This study has shown that these unwanted 361 side reactions could be minimized (i.e. reduced to $<5 \%$ ) by controlling the relative HEMA:TBD ratio and the reaction time.

This study has also concluded that TBD is a more efficient ROP catalyst when compared to lipases. In fact, it has been well documented that lipases cannot discriminate ROP from the transesterification sub-processes in the presence of cleavable ester initiators such as HEMA, even at low monomer conversion. ${ }^{[16,17]}$ This leads to the production of di-methacrylated macromolecular chains and an inability to produce well-defined polymers. By comparison, this study has demonstrated that, by using TBD as a catalyst in small scale reactions and adopting the simple precautions of controlling the catalyst concentration and reaction times, monomethacrylated chains with no (for HEMA initiated PDLLA and HEMA initiated PTMC) or limited ( $<5 \%$ for HEMA initiated PCL) di-methacrylated chains can be produced. Additionally, this ROP reaction can be achieved with reagents that are readily available and under mild reaction conditions, i.e. room temperature and atmosphere, in comparison to tin octoate that 374 requires high temperature and longer reaction time. All the aforementioned properties of TBD 375 will facilitate the production of biodegradable polymers bearing an active (metha)acrylic group with the view to produce novel biodegradable architectures not achievable with one synthetic 377 approach alone. ${ }^{[27]}$ In particular, HEMA-terminated-polyester macromonomers have been used 378 in copolymerization with a plethora of methacrylic-acrylic monomers, ${ }^{[27]}$ to produce graft379 copolymers via controlled radical polymerization techniques such as ATRP ${ }^{[27]}$ and RAFT. ${ }^{[27]}$ 


\section{WILEY-VCH}

By rendering more accessible and easier the ROP step it would quickly broaden the number of possible novel "smart materials" that can be explored and developed.

Furthermore, it has also been shown that it is possible to produce block copolymers via sequential ROP reaction from a preformed macroinitiator using the same processing strategies with TBD. This confirms TBD as an accessible catalyst for solution-phase ROP of cyclic esters initiated by cleavable esters and, as the macro-initiators chosen were synthesized from caprolactone, it also confirms the high level of hydroxyl termination when the correct synthetic strategies were applied. Thus, TBD has been shown to be a practical alternative to metal-based catalysts that exhibits higher selectivity than Lipases in the reactions tested.

\section{Acknowledgements}

This work was supported by the Engineering and Physical Sciences Research Council [grant numbers EP/N024818/1, EP/N03371X/1, EP/H005625/1, EP/N006615/1]; grant names: Formulation for 3D printing, creating a plug and play platform for a disruptive U.K. industry, Radiotherapy activated materials for enhanced cancer treatments, Bar-Coded Biomaterials Designing Self-Authenticating Medicines and Programme Grant for Next Generation Biomaterials Discovery. This work was also funded by the Royal Society (Wolfson Research Merit Award WM150086 (to CA).

Keywords: Ring-Opening Polymerization, triazabicyclodecene (TBD) catalyst, hydroxyethylmethacrylate (HEMA) initiated, monofunctional -methacrylate polyesters

\section{Data access statement}

All raw data created during this research are openly available from the corresponding author (vincenzo.taresco@nottingham.ac.uk) and at the University of Nottingham Research Data 


\section{WILEY-VCH}

407 Management Repository (https://rdmc.nottingham.ac.uk/) and all analyzed data supporting this

408 study are provided as supplementary information accompanying this paper.

409

410

\section{References}

412 [1] C. Jérôme, P. Lecomte, Adv. Drug Deliv. Rev. 2008, 60, 1056.

413 [2] J. Feng, R. X. Zhuo, X. Z. Zhang, Prog. Polym. Sci. 2012, 37, 211.

414 [3] R. Tong, Ind. Eng. Chem. Res. 2017, 56, 4207.

415 [4] H. Seyednejad, A. H. Ghassemi, C. F. Van Nostrum, T. Vermonden, W. E. Hennink, J. $416 \quad$ Control. Release 2011, 152, 168.

417 [5] Y. Zhang, D. Chu, M. Zheng, T. Kissel, S. Agarwal, Polym. Chem. 2012, 3, 2752.

418 [6] Y. Zhao, G. He, W. Guo, L. Bao, M. Yi, Y. Gong, S. Zhang, Polym. Chem. 2016, 7, $419 \quad 5698$.

420 [7] Y. You, C. Hong, W. Wang, W. Lu, C. Pan, Macromolecules 2004, 37, 9761.

421 [8] H. Shinoda, K. Matyjaszewski, Macromolecules 2001, 34, 6243.

422 [9] M. Le Hellaye, C. Lefay, T. P. Davis, M. H. Stenzel, C. Barner-Kowollik, J. Polym. 423 Sci. Part A Polym. Chem. 2008, 46, 3058.

424 [10] R. Ferrari, C. Colombo, M. Dossi, D. Moscatelli, Macromol. Mater. Eng. 2013, 298, $425 \quad 730$.

426 [11] R. Ferrari, Y. Yu, M. Morbidelli, R. A. Hutchinson, D. Moscatelli, Macromolecules $427 \quad 2011,44,9205$.

428 [12] J. A. Wallach, S. J. Huang, Biomacromolecules 2000, 1, 174.

429 [13] J. Kiehl, C. Delaite, S. Bistac, A. S. Schuller, H. Farge, Polymer (Guildf). 2012, 53, $430 \quad 694$.

431 [14] F. F. Wolf, N. Friedemann, H. Frey, Macromolecules 2009, 42, 5622.

432 [15] J. Xu, J. Song, S. Pispas, G. Zhang, Polym. Chem. 2014, 5, 4726. 


\section{WILEY-VCH}

433 [16] M. Takwa, Y. Xiao, N. Simpson, E. Malmstrom, K. Hult, C. E. Koning, A. Heise, M.

434

435

436

437

438

439

440

441

442

443

444

445

446

447

448

449

450

451

452

453

454

455

456

457

458 Martinelle, Biomacromolecules 2008, 9, 704.

[17] Y. Xiao, M. Takwa, K. Hult, C. E. Koning, A. Heise, M. Martinelle, Macromol. Biosci. 2009, 9, 713.

[18] B. G. G. Lohmeijer, R. C. Pratt, F. Leibfarth, J. W. Logan, D. A. Long, A. P. Dove, F. Nederberg, J. Choi, C. Wade, R. M. Waymouth, J. L. Hedrick, Macromolecules 2006, 39,8574 .

[19] N. E. Kamber, W. Jeong, R. M. Waymouth, R. C. Pratt, B. G. G. Lohmeijer, J. L. Hedrick, Chem. Rev. 2007, 107, 5813.

[20] U. Capasso Palmiero, M. Sponchioni, N. Manfredini, M. Maraldi, D. Moscatelli, Polym. Chem. 2018, 9, 4084.

[21] H. Qian, A. R. Wohl, J. T. Crow, C. W. MacOsko, T. R. Hoye, Macromolecules 2011, $44,7132$.

[22] M. Labet, W. Thielemans, Chem. Soc. Rev. 2009, 38, 3484.

[23] R. C. Pratt, B. G. G. Lohmeijer, D. A. Long, R. M. Waymouth, J. L. Hedrick, J. Am. Chem. Soc. 2006, 128, 4556.

[24] S. A. Pendergraph, G. Klein, M. K. G. Johansson, A. Carlmark, RSC Adv. 2014, 4, 20737.

[25] P. K. Kuroishi, M. J. Bennison, A. P. Dove, Polym. Chem. 2016, 7, 7108.

[26] O. Persenaire, M. Alexandre, P. Dege'e, P. Dubois, Biomacromolecules 2001, 2, 288.

[27] X. Guo, B. Choi, A. Feng, S. H. Thang, X. F. Guo, B. Choi, A. C. Feng, S. H. Thang, Macromol. Rapid Commun. 2018, 1800479. 


\section{WILEY-VCH}

459 TOC

460 Methacrylated block co-polyesters were synthesized via TBD catalyzed ROP. TBD has

461 been successfully employed as an active and selective catalyst for HEMA- initiated ROP of LA,

462 TMC, and CL in order to synthesize, under mild and standard laboratory conditions,

463 homopolymers and block copolymers with controlled molecular weight, low polydispersity and

464 a mono-methacrylate final architecture.

465

466

467

468

469

470

471

472

473

474

475

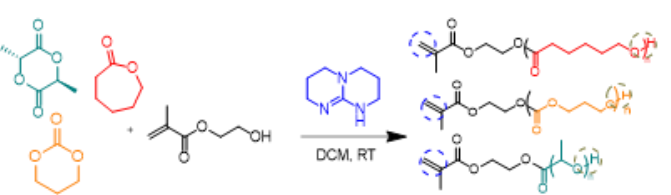

Laura A. Ruiz-Cantu, Amanda K. Pearce, Laurence Burroughs, Thomas M. Bennett, Catherine E. Vasey, Ricky Wildman, Derek J. Irvine*, Cameron Alexander*, and Vincenzo Taresco*

\section{Synthesis of Methacrylate-Terminated Block Copolymers with Reduced} Transesterification by Controlled Ring-Opening Polymerization

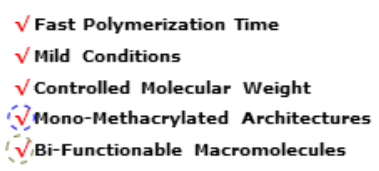

$\checkmark$ Fast Polymerization Time

$\sqrt{ }$ Mild Conditions

$\checkmark$ Controlled Molecular Weight

C. Mono-Methacrylated Architectures

V $\sqrt{\text { Bi-Functionable Macromolecules }}$ 


\section{WILEY-VCH}

\section{Captions to Figures, Schemes and Tables}

Scheme 1. $\varepsilon$-CL ROP dual activation mechanism in presence of a generic alcohol catalyzed by TBD.

Scheme 2. Schematic of TBD triggered self-acyl transfer of the methacrylic group of HEMA producing ethylene bis-methacrylate and ethylene glycol from 2 equivalent of HEMA.

Figure 1. Comparison of the kinetic profiles showing the level of transesterification achieve when varying the relative quantities of HEMA and TBD. An unpaired t-test $(\mathrm{p}<0.05$ indicating significant difference) analysis was performed at each time-point and confirmed that significant differences were observed at each time point between the two selected initiator:catalyst ratios.

Figure 2. (Top) LA reaction scheme, polymer stoichiometry takes into account the corrected conversion. (bottom) Full ${ }^{1} \mathrm{H}-\mathrm{NMR}$ spectrum of purified HEMAPDLLA 5000, in the 7.5 to 1.0 ppm spectral range. Note: residual catalyst and diethyl ether in the spectral range of 4.0 to 3.2 ppm.

Figure 3. A) HSQC NMR spectra of PDLLA, showing the presence of a single methacrylic species (inlay) in the final polymer and confirming the presence of a single HEMA end group for each polymeric chain. Peaks assigned a1 and b1 represent the two vinyl protons and c1 represents the vinylic carbon. B) $\mathrm{HMBC}{ }^{1} \mathrm{H}-{ }^{13} \mathrm{C}$ NMR spectra of HEMA initiated PDLLA, demonstrating the presence and multiple bond correlations confirming (inlay top) a single methyl (methacrylate) species and (inlay bottom) a single carbonyl (methacrylate) species in the final polymer.

Figure 4. (Top) HEMA initiated TMC reaction scheme, polymer stoichiometry takes into account the corrected conversion and (Bottom) ${ }^{1}$ HNMR spectrum. Inset, the vinyl region which exhibits only two peaks as expected, demonstrating a satisfactory controlled ROP without sidetransesterification.

Figure 5. (Top) HEMAPCL reaction scheme, polymer stoichiometry takes into account the corrected conversion. (Bottom) ${ }^{1} \mathrm{H}-\mathrm{NMR}$ spectrum of HEMAPCL (synthesized employing 1.5 


\section{WILEY-VCH}

$516 \%$ mol:mol TBD) (red traces) showing a reduction of the vinyl peaks related to the

517 transesterification sub-products in the range of 6.2-5.5 ppm. (Inset) Difference in magnitude of 518 transesterification between the polymer synthesized with $2.5 \%$ (blue trace) and $1.5 \%$ (red trace) 519 catalyst.

520 Figure 6. LEFT. Stacking ${ }^{1} \mathrm{H}-\mathrm{NMR}$ spectra, in the region between 6.5 to $3.5 \mathrm{ppm}$, of 521 HEMAPCL macroinitiator (red trace), HEMAPCL-PTMC (green trace) and HEMAPCL522 PDLLA (black trace) block copolymers showing that they characteristic peaks for PTMC and 523 PLA end groups, there PCL, PTMC and PDLLA end group functionalities are shown as *, $\Delta$ 524 and + respectively. RIGHT. GPC traces of HEMAPCL, HEMAPCL-PTMC and the 525 HEMAPCL-PDLLA block copolymers. 


\section{WILEY-VCH}

543 Table 1. Characterization data for ROP polymers synthesized using HEMA, TBD. DP $0=$

544 Theoretical $\mathrm{M}_{\mathrm{n}}, \mathrm{DP}_{\mathrm{e}}=$ Experimentally observed $\mathrm{M}_{\mathrm{n}}(\mathrm{NMR})$ post-purification and $\mathrm{DP}_{\mathrm{c}}$ is the

545 conversion corrected $\mathrm{M}_{\mathrm{n}}$.

\begin{tabular}{|c|c|c|c|c|c|c|c|c|}
\hline & $\begin{array}{c}\text { Polymer } \\
\text { (TBD Mole \% wrt } \\
\text { Monomer ) }\end{array}$ & $\begin{array}{l}\text { Time } \\
\text { (Min) }\end{array}$ & $\mathrm{DP}_{0}: \mathrm{DP}_{\mathrm{c}}: \mathrm{DP}_{\mathrm{e}}$ & $\begin{array}{c}\mathbf{M n}^{\mathrm{a}} \\
(\mathbf{G P C}) \\
\left(\mathrm{g} \mathrm{mol}^{-1}\right)\end{array}$ & $\begin{array}{c}\mathbf{M n}^{\mathbf{b}} \\
\left(\mathrm{NMR}^{-}\right) \\
\left(\mathrm{g} \mathrm{mol}^{-1}\right)\end{array}$ & Đ & $\begin{array}{c}\text { Yield }^{\mathrm{c}} \\
(\%)\end{array}$ & $\begin{array}{c}\text { Trans } \\
(\%)\end{array}$ \\
\hline 1 & $\begin{array}{c}\text { HEMAPDLLA } \\
(1.0)\end{array}$ & $<3$ & $35: 33: 35$ & 4930 & 5090 & 1.18 & 95 & -- \\
\hline 2 & $\begin{array}{c}\text { HEMAPDLLA } \\
(1.0)\end{array}$ & $<3$ & $45: 43: 43$ & 7860 & 6120 & 1.21 & 95 & - \\
\hline 3 & $\begin{array}{c}\text { HEMAPTMC } \\
(1.0)\end{array}$ & $<3$ & $49: 45: 50$ & 3600 & 5175 & 1.25 & 90 & -- \\
\hline 4 & $\begin{array}{c}\text { HEMAPCL } \\
(2.5)\end{array}$ & 120 & 45:--:-- & 3860 & --- & 1.51 & 75 & $>30$ \\
\hline 5 & $\begin{array}{c}\text { HEMAPCL } \\
(1.5)\end{array}$ & 120 & $22: 17: 24$ & 3155 & 2780 & 1.14 & 75 & $<3$ \\
\hline 6 & $\begin{array}{c}\text { HEMAPCL } \\
(1.5)\end{array}$ & 120 & $45: 34: 35$ & 4310 & 4170 & 1.13 & 75 & $<5$ \\
\hline 7 & $\begin{array}{c}\text { HEMAPCL- } \\
\text { PTMC } \\
(1.0) \\
\end{array}$ & $<3$ & $\begin{array}{c}35+10: 35+8: \\
35+10\end{array}$ & 6295 & 5190 & 1.09 & 80 & $<3$ \\
\hline 8 & $\begin{array}{c}\text { HEMAPCL- } \\
\text { PDLLA } \\
(1.0)\end{array}$ & $<3$ & $\begin{array}{c}35+35: 35+23 \\
: 35+28\end{array}$ & 8125 & 8200 & 1.15 & 80 & $<3$ \\
\hline
\end{tabular}

a) Referenced to PMMA standards, ${ }^{\text {b) }}$ calculated by ${ }^{1} \mathrm{H}-\mathrm{NMR},{ }^{\text {c) }}$ Quoted to nearest $5 \%$ 


\section{WILEY-VCH}

$559 \quad$ Figure 1
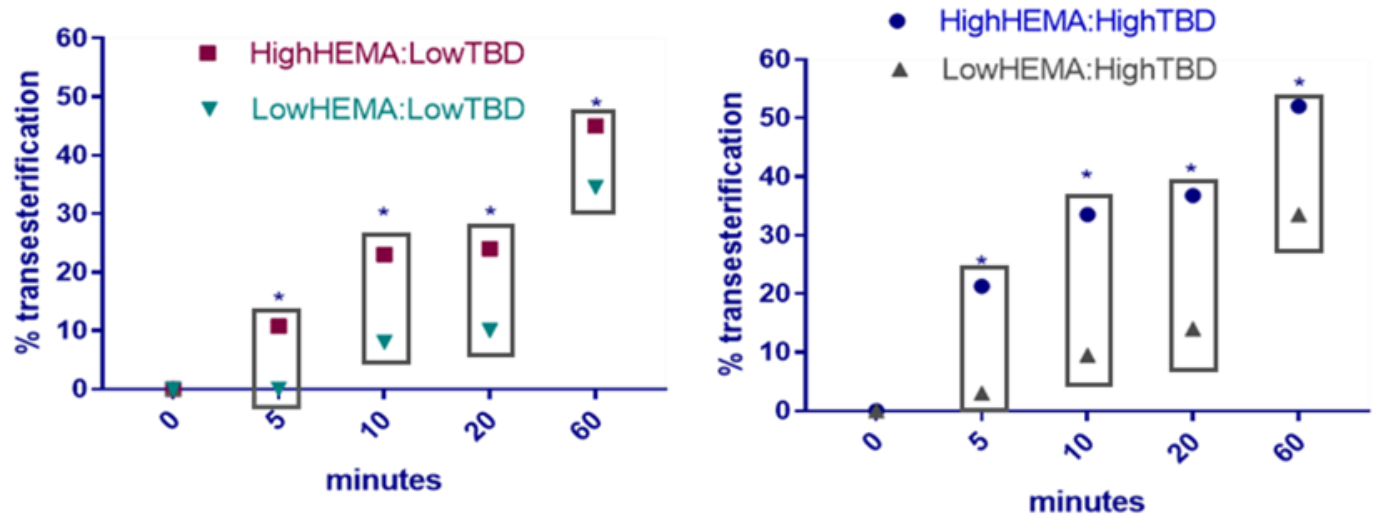

560

561

562

563

564

565

566

567

568

569

570

571

572

573

574

575

576

577

578 


\section{WILEY-VCH}

579

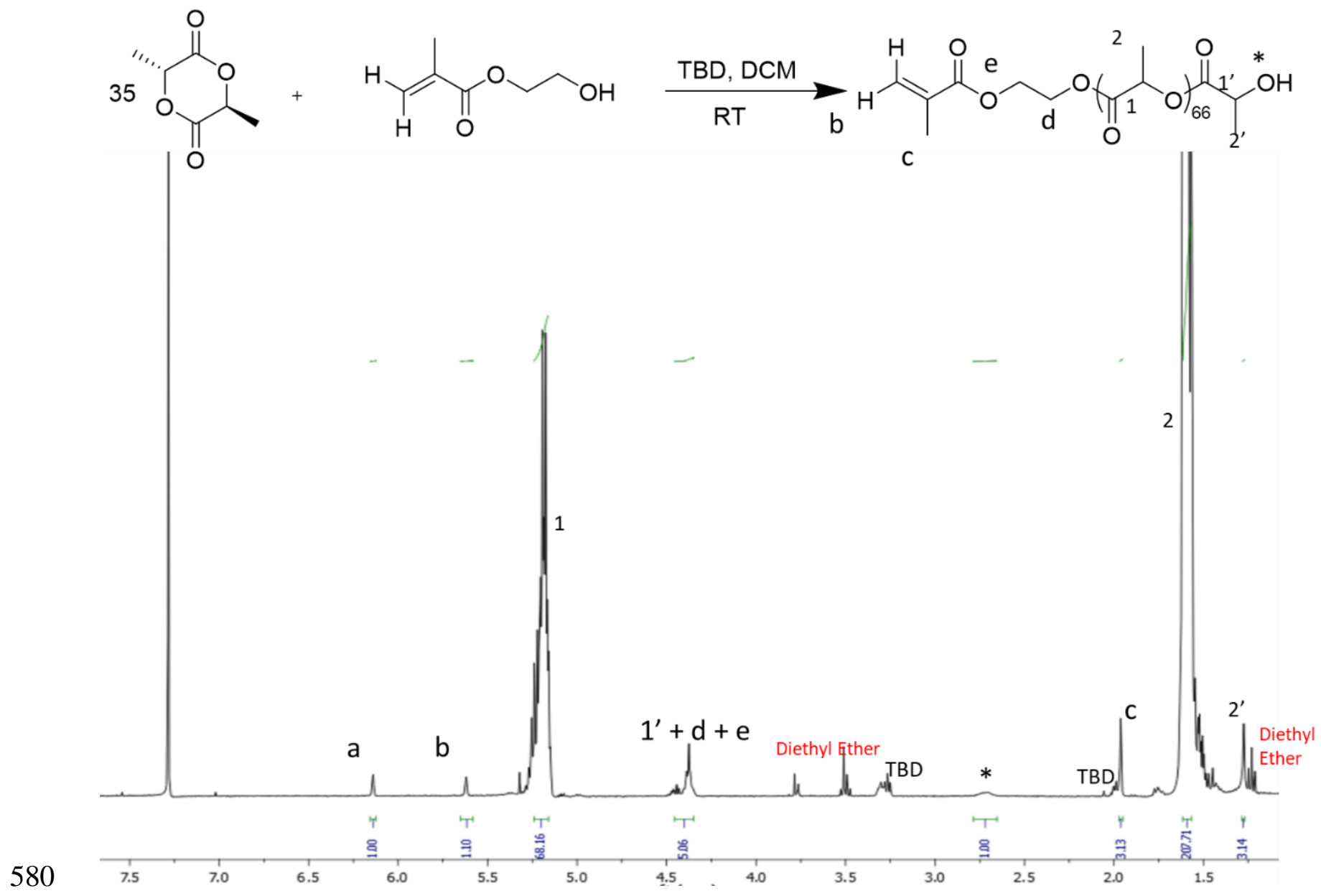

581

582

583

584

585

586

587

588

589

590

591

592

593

594

595

596

597

598

599

600

601

602

Figure 2

(9)




\section{WILEY-VCH}

603 Figure 3

604

A

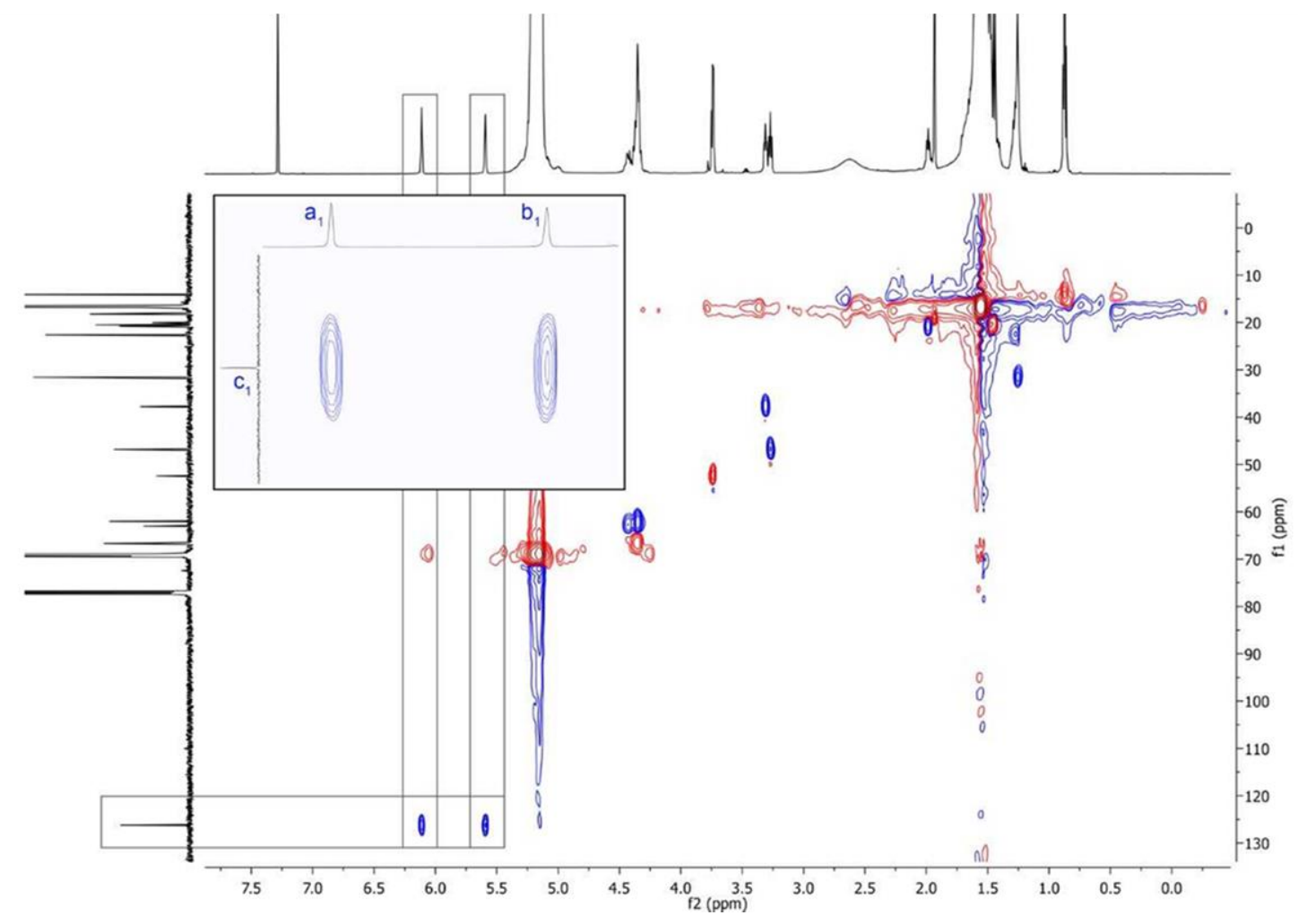

605

606

B

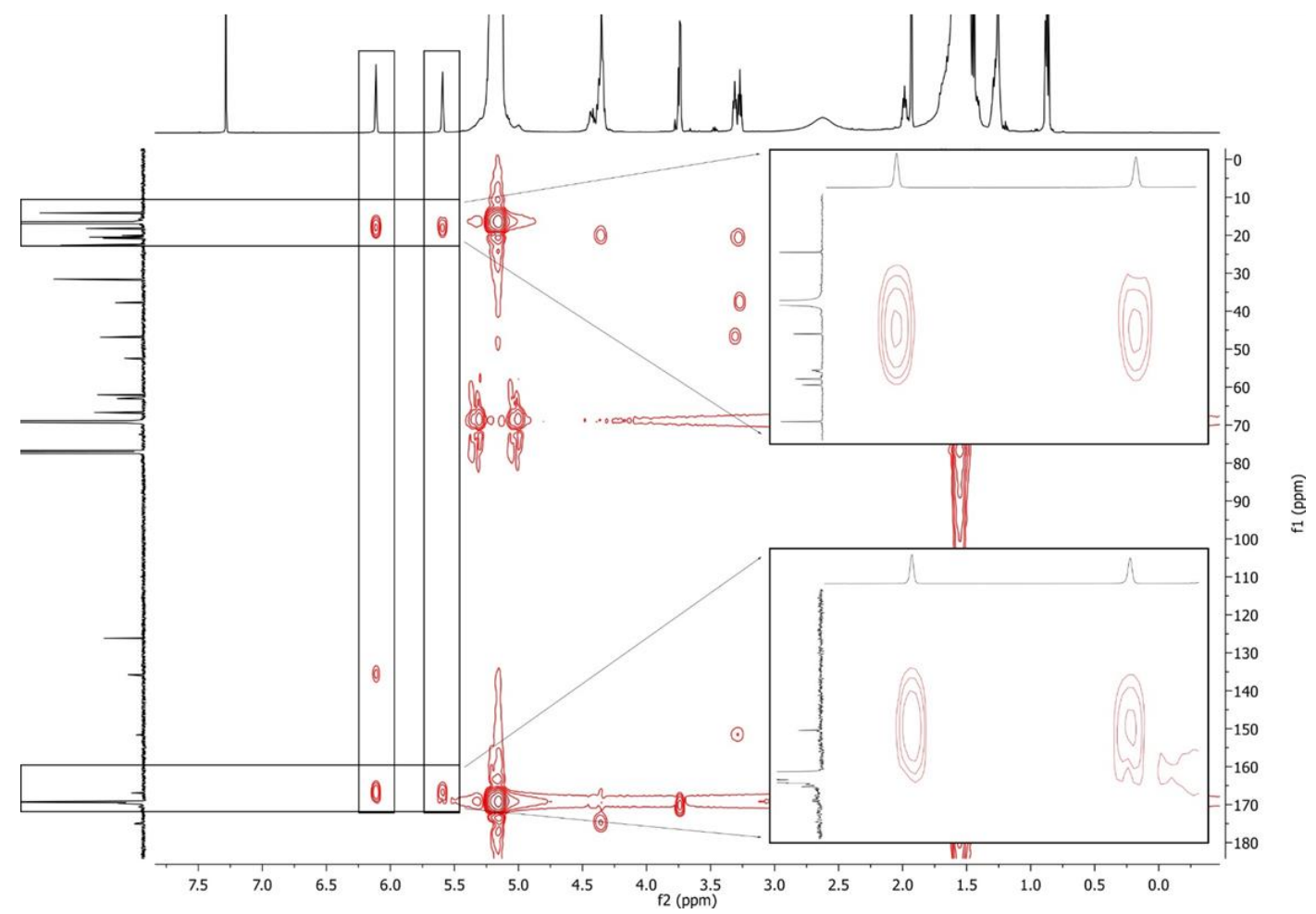




\section{WILEY-VCH}

608

$609 \quad$ Figure 4

610

611<smiles>C=C(C)C(=O)OCCOC(=O)OCCCO[13CH3]</smiles>

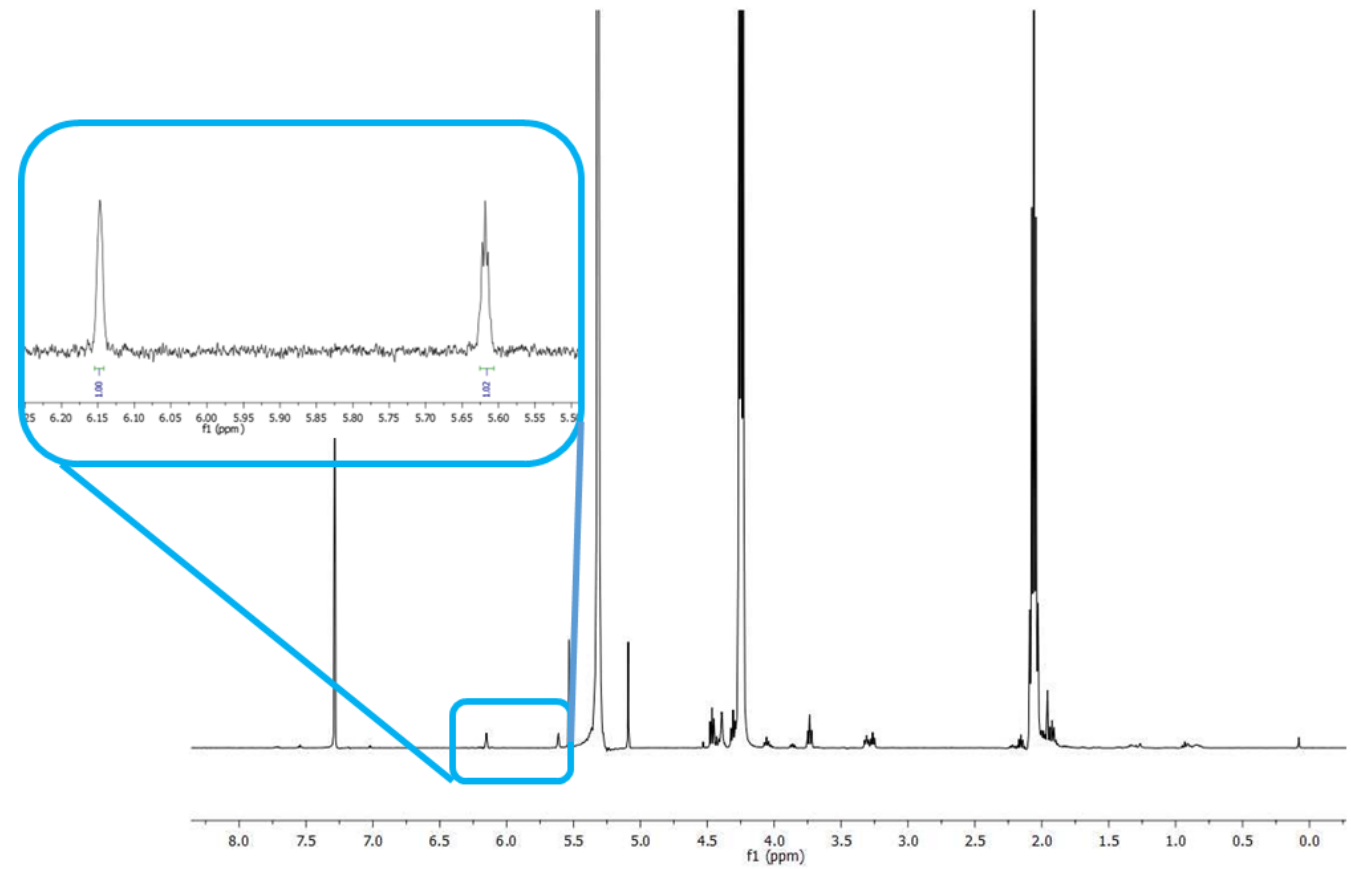

613

614

615

616

617

618

619

620

621

622

623

624

625

626

627

628

629

630

631

632

633

634

635 


\section{WILEY-VCH}

$636 \quad$ Figure 5

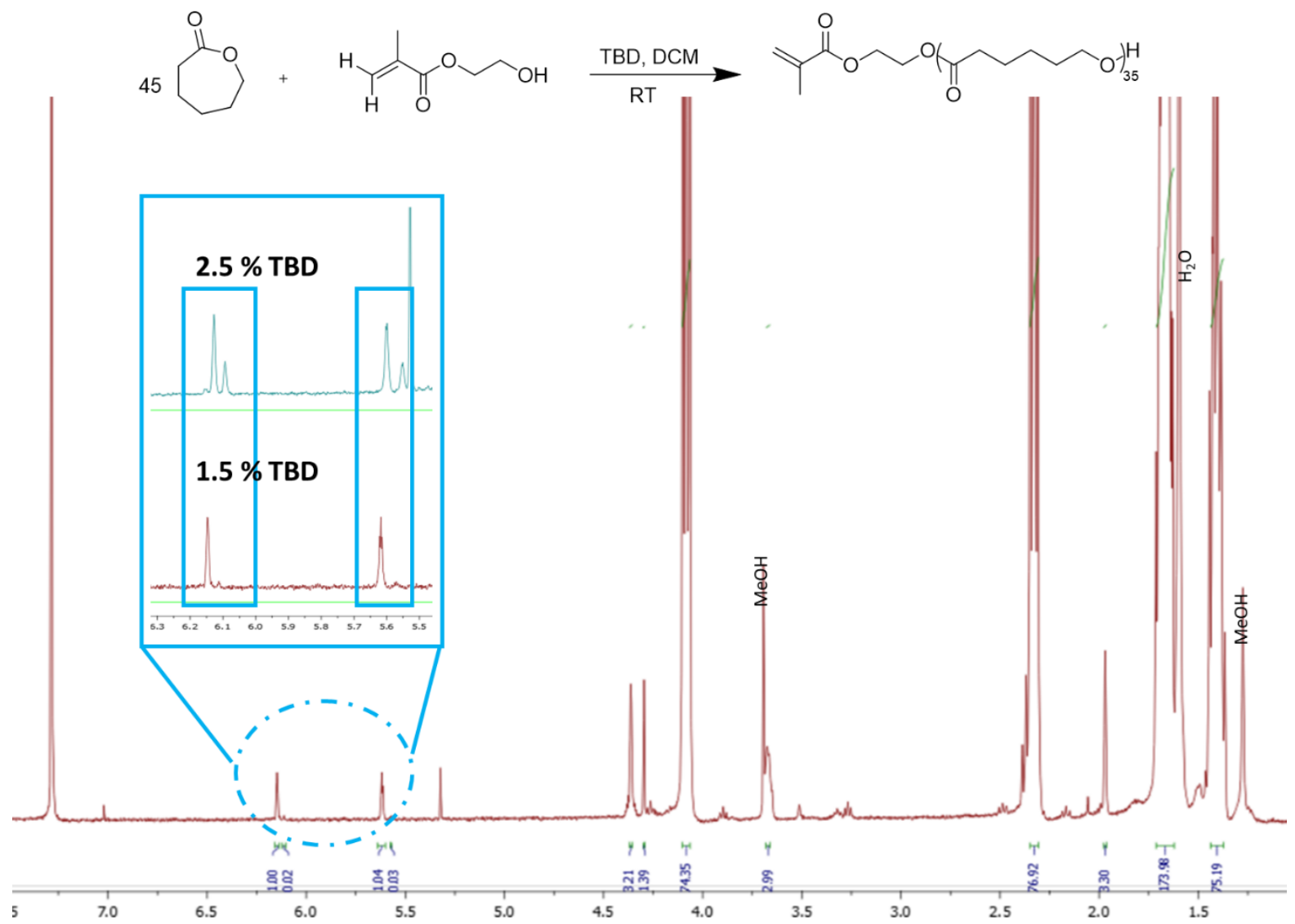

638

639

640

641

642

643

644

645

646

647

648

649

650

651

652

653

654

655

656

657

658

659

660

661

662 


\section{WILEY-VCH}

663

664

665

666

667

668

669

670

671

672

673

674

675

676

677

678

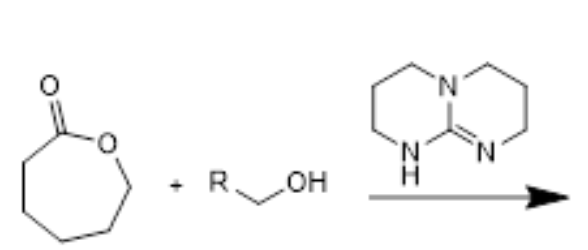

Scheme 1

\section{Figure 6}

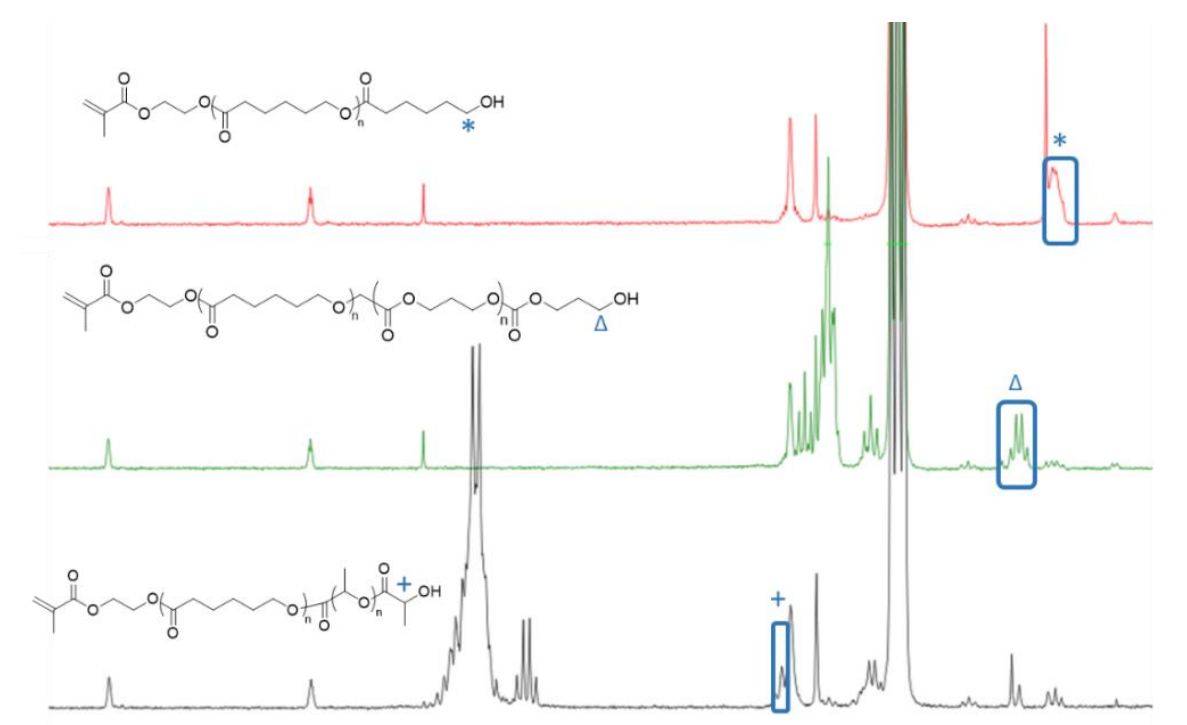

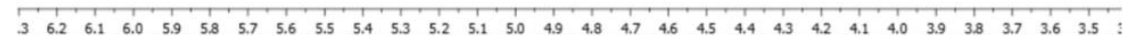
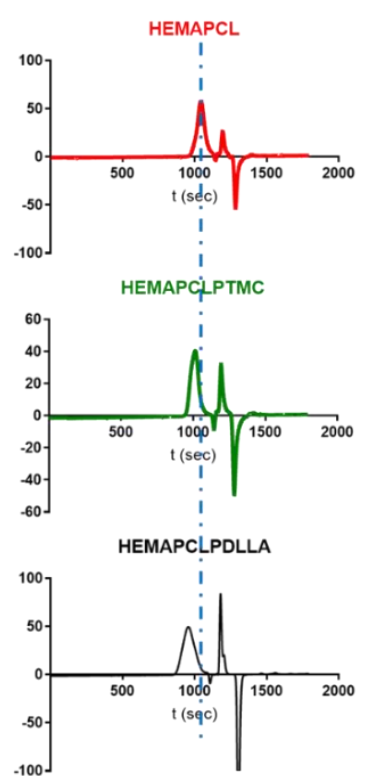<smiles>CCOCCOC(=O)NN1CCCN2CCCCCC21</smiles><smiles>[R]COC1(OC)CCCCC[C@]1(C)OC</smiles>

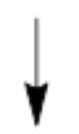<smiles>[R]COC(=O)CCCCCO</smiles><smiles>C1CN=C2NCCCN2C1</smiles> 
WILEY-VCH

686 Scheme 2

687

2<smiles>CC=C(C)C(=O)OCCO</smiles>

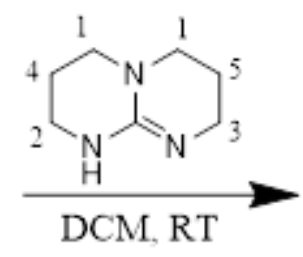

688

689

690

691

692

693

694

695

696

697

698

699

700

701

702

703

704

705

706

707

708

709

710

711

712

713

714

715

716

717

718

719

720

721

722

723

724

725

726

727

728

729 


\section{WILEY-VCH}

\section{Supporting Information}

\section{Synthesis of Methacrylate-Terminated Block Copolymers with Reduced Transesterification by Controlled Ring-Opening Polymerization}

Laura A. Ruiz-Cantu ${ }^{a}$, Amanda K. Pearce ${ }^{b}$, Laurence Burroughs ${ }^{b}$, Thomas M. Bennett ${ }^{c}$, Catherine E. Vasey ${ }^{b}$, Ricky Wildman ${ }^{a}$, Derek J. Irvine ${ }^{a *}$, Cameron Alexander $^{b} *$ and Vincenzo $\operatorname{Taresco}^{b *}$

Dr. L. A. Ruiz-Cantu, Dr., Prof. R. Wildman, Prof. D.J. Irvine,

Faculty of Engineering, University of Nottingham, University Park, Nottingham, NG7 2RD, UK.

Dr. T. M. Bennett

School of Chemistry, University of Nottingham, University Park, Nottingham NG7 2RD, UK. Dr. A. K. Pearce, Dr. L. Burroughs, C. E. Vasey, Prof. C. Alexander and Dr. V. Taresco.

School of Pharmacy, University of Nottingham, University Park, Nottingham NG7 2RD, UK.

E-mail: $\quad$ derek.irvine@nottingham.ac.uk, $\quad$ cameron.alexander@nottingham.ac.uk vincenzo.taresco@nottingham.ac.uk.

Figure S1. NMR kinetics of HEMA self-transesterification in presence of TBD.

Figure S2. Kinetic profile of HEMAPCL ROP.

Figure S3. HEMAPCL reaction scheme and detailed NMR spectra.

Figure S4. HMBC ${ }^{1} \mathrm{H}^{13} \mathrm{C}$ NMR spectra of HEMAPCL.

Figure S5. ${ }^{1} \mathrm{H}-\mathrm{NMR}$ of HEMAPCL polymers showing full integration 


\section{WILEY-VCH}

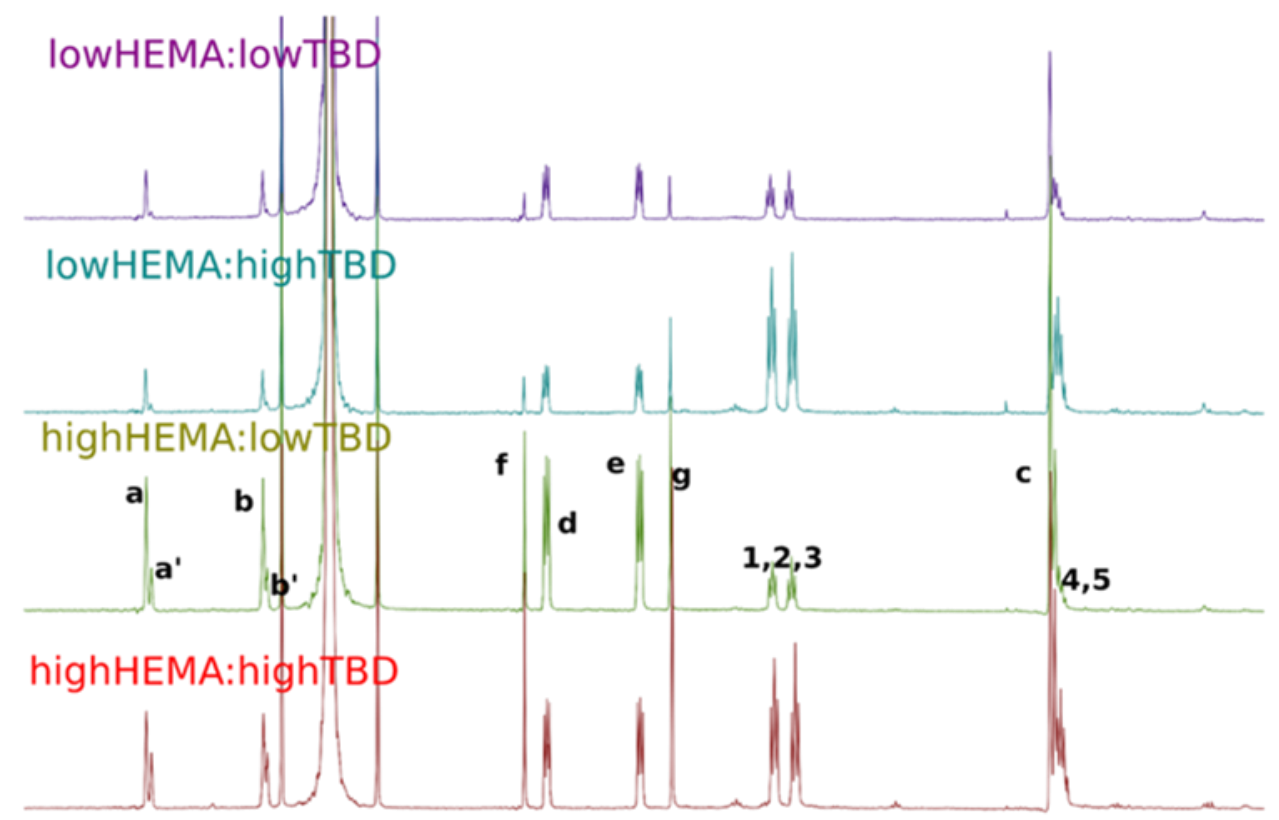

767 Figure S1. NMR spectra confirming feed ratio (HEMA:TBD) dependent presence of both 


\section{WILEY-VCH}

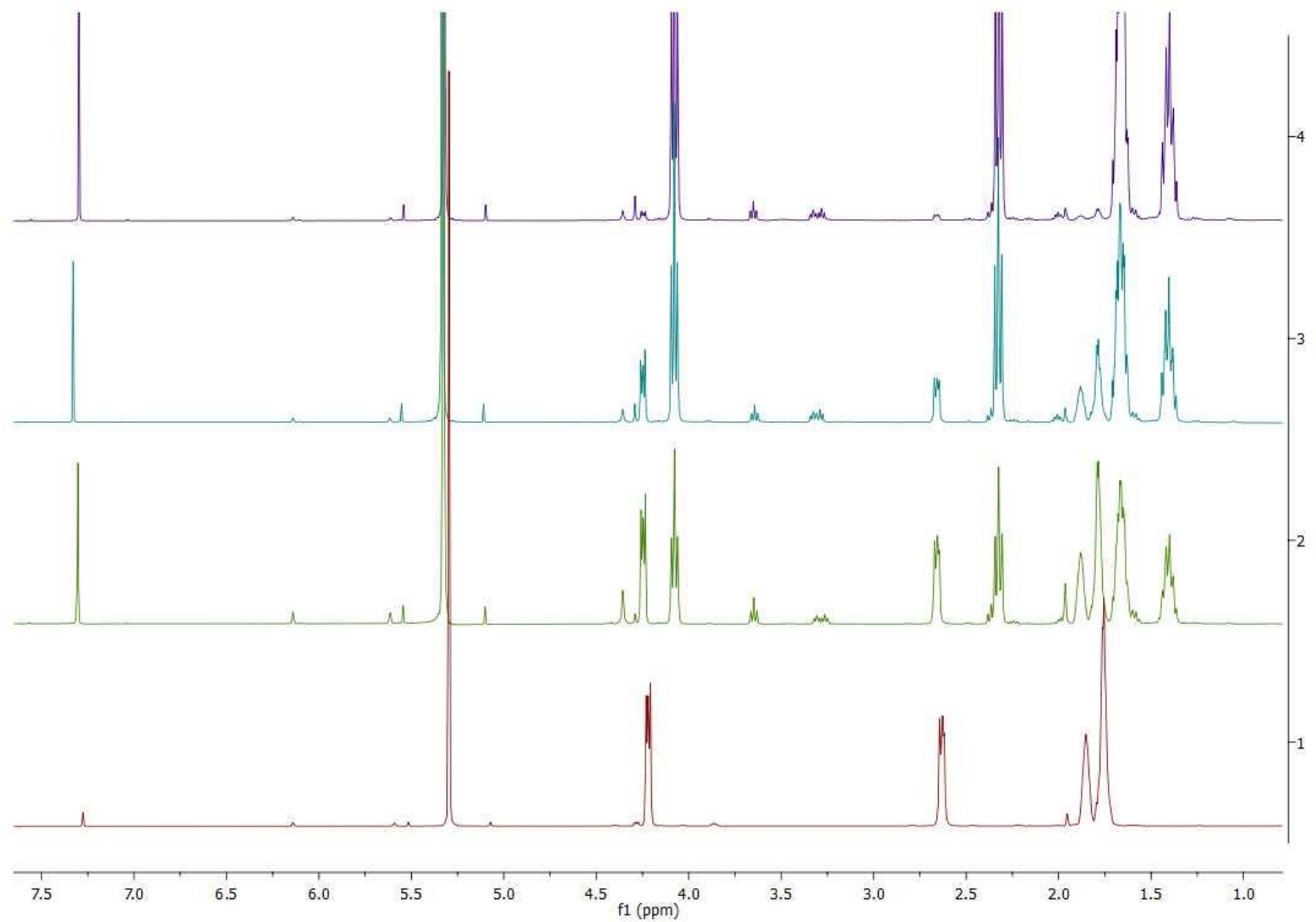

Figure S2: Kinetic profile of HEMAPCL ROP at 0, 20, 60, and 240 minutes (from bottom to top). Note: $240 \mathrm{~min}$ is shown to justify the full conversion of monomer to polymer.

776 


\section{WILEY-VCH}

A

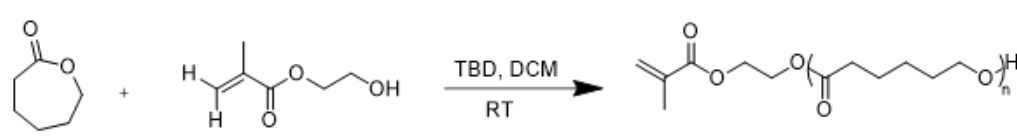
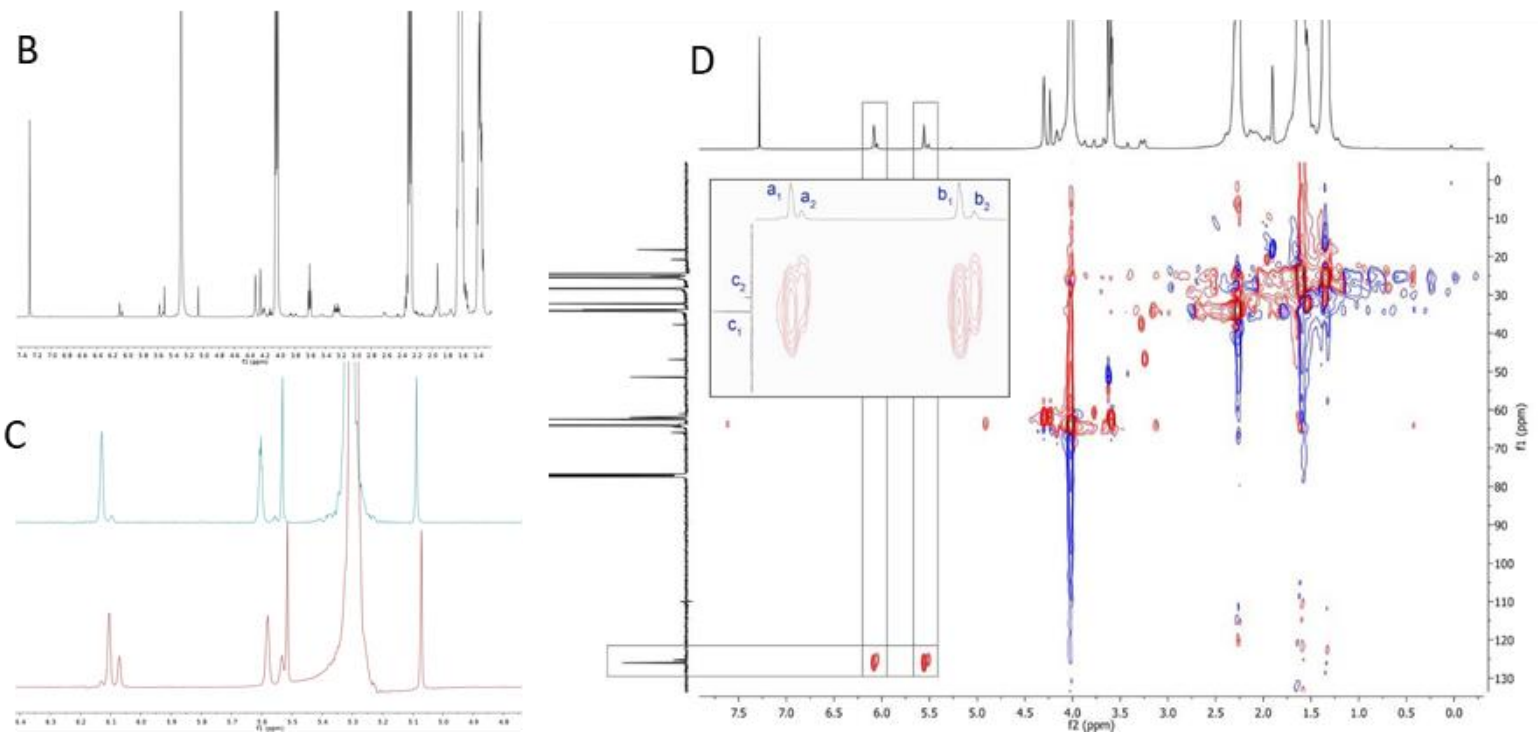

Figure S3. A) CL scheme of reaction. B) Full ${ }^{1} \mathrm{H}-\mathrm{NMR}$ spectrum HEMAPCL. C) Stacked ${ }^{1} \mathrm{H}-$

NMR methacrylic protons region; peaks splitting in two limiting acyl transfer conditions (6.1$5.5 \mathrm{ppm}$ ). D) HSQC NMR spectra of HEMAPCL, confirming the presence of a two different methacrylic species (inlay) in the final polymer. Peaks assigned a1, a2, b1 and b2 represent the 4 vinyl proton species, and c1 and c 2 represent the 2 vinylic carbon species in the final polymer. This effect is easily observed when a high amount of TBD was used leading to an uncontrolled polymer functionalization. 


\section{WILEY-VCH}

802

803

804

805

806

807

808

809

810

811

812

813

814

815

816

817

818

819

820

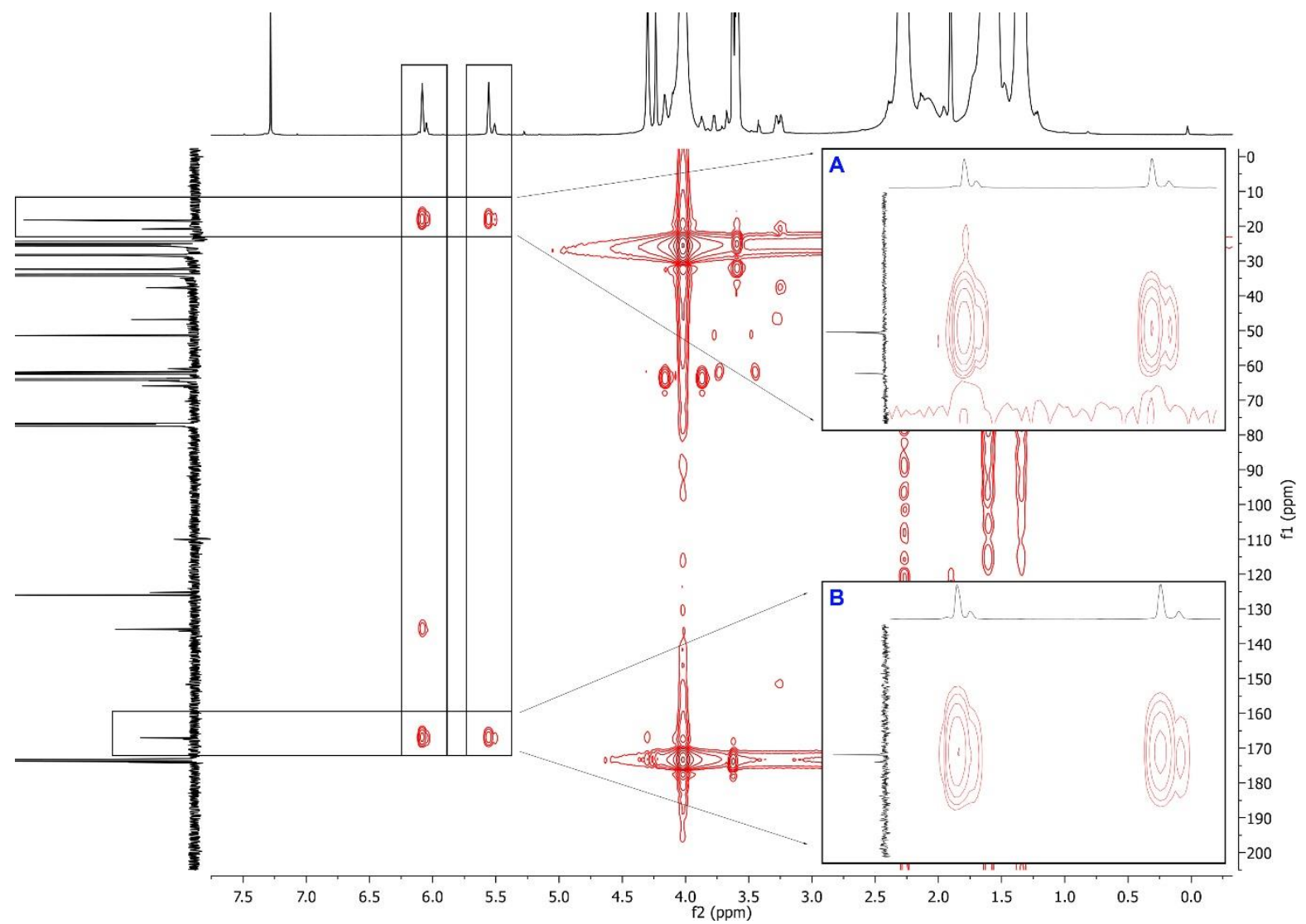

Figure S4. HMBC ${ }^{1} \mathrm{H}_{-}{ }^{13} \mathrm{C}$ NMR spectra of HEMAPCL, demonstrating the presence and multiple bond correlations confirming (inlay a) two different methyl (methacrylate) species and (inlay b) two different carbonyl (methacrylate) species in the final polymer. This effect is easily observed when a high amount of TBD was used leading to an uncontrolled polymer functionalization. 
WILEY-VCH

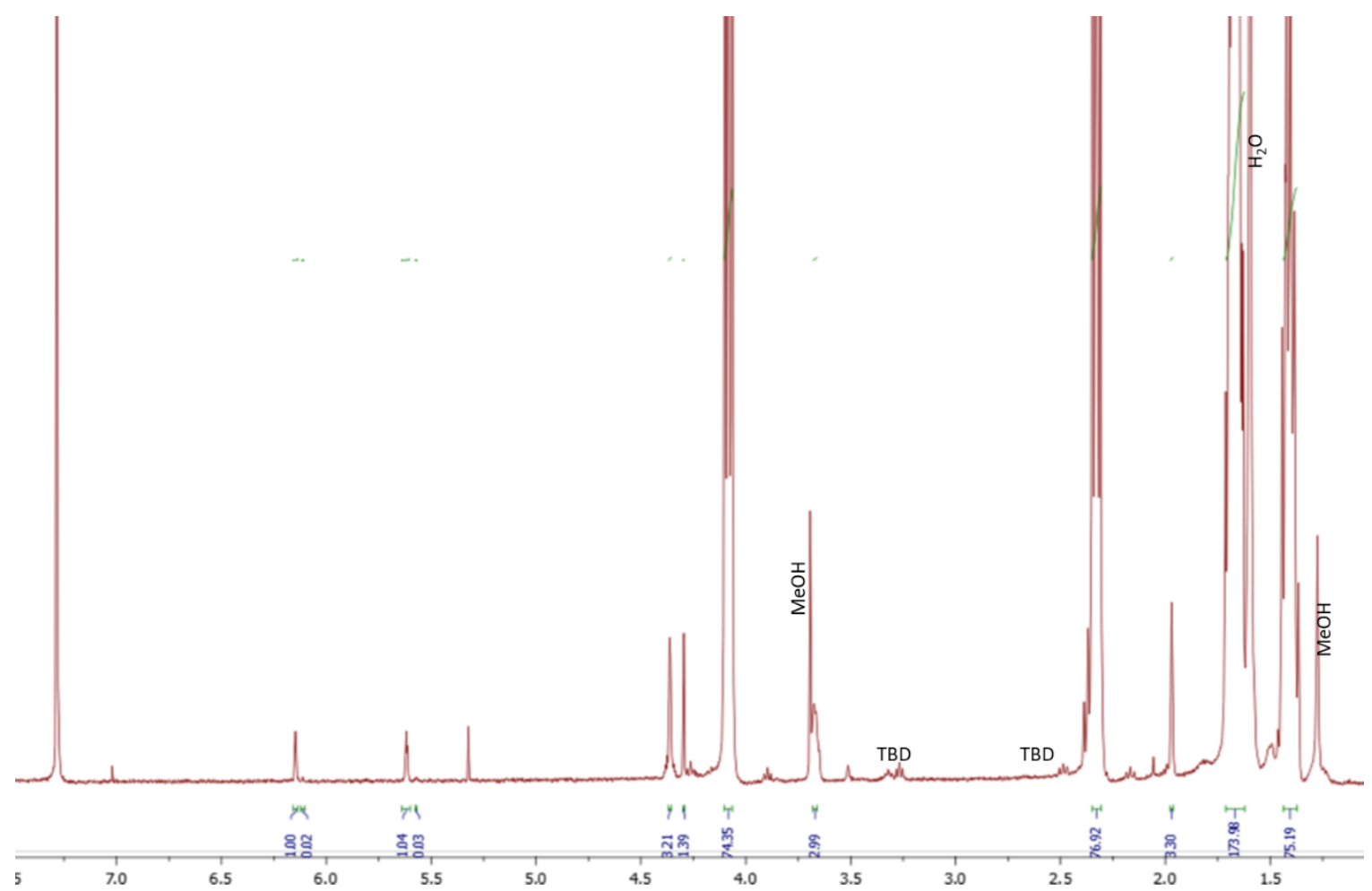

822 Figure S5. ${ }^{1} \mathrm{H}-\mathrm{NMR}$ of HEMAPCL polymers showing full integration, vinyl peaks splitting 823 ratios and PCLHEMA functionality proportions.

824

825

826 